\title{
Projeto Rede de Parceiros Multiplicadores de Esporte Educacional: impacto na
}

\section{prática pedagógica}

\author{
Project Network of Multiplying Partners of Educational Sport: impact on the pedagogical practice \\ Proyecto Red de Socios Multiplicadores del Deporte Educativo: impacto en la práctica pedagógica
}

Recebido: 01/01/2021 | Revisado: 05/02/2021 | Aceito: 08/02/2021 | Publicado: 15/02/2021

\author{
Patrícia da Rosa Louzada da Silva \\ ORCID: https://orcid.org/0000-0002-0259-299X \\ Universidade Federal de Pelotas, Brasil \\ E-mail: patricia_prls@hotmail.com \\ Leontine Lima dos Santos \\ ORCID: https://orcid.org/0000-0002-9686-2339 \\ Universidade Federal de Pelotas, Brasil \\ E-mail: leozinhaesef@hotmail.com \\ Fabiana Celente Montiel \\ ORCID: https://orcid.org/0000-0002-9921-6703 \\ Instituto Federal Sul-rio-grandense, Brasil \\ E-mail: fabianamontiel@ifsul.edu.br \\ Eraldo dos Santos Pinheiro \\ ORCID: https://orcid.org/ 0000-0002-5749-1512 \\ Universidade Federal de Pelotas, Brasil \\ E-mail: esppoa@gmail.com
}

\begin{abstract}
Resumo
A formação de professores/as de Educação Física, entre os anos de 2013 e 2017, foi tema da parceria estabelecida entre o Instituto Esporte \& Educação (IEE) e nove prefeituras de cidades da região sul do Estado do Rio Grande do Sul (RS). Este estudo objetivou compartilhar a experiência do Projeto Rede de Parceiros Multiplicadores de Esporte Educacional (PRPMEE), no Estado do RS, no que se refere à implementação, realização e efetivação de práticas em Esporte Educacional, além de apontar o impacto da formação continuada proposta na prática pedagógica de um professor de Educação Física, escolhido intencionalmente, do município de Arroio Grande. Os passos metodológicos foram traçados por meio de uma pesquisa descritiva de natureza qualitativa e a análise das informações se deu a partir da técnica de triangulação dos dados proposta por Triviños. Os instrumentos utilizados para coleta das informações foram: entrevista semiestruturada; observação da prática pedagógica; materiais pedagógicos fornecidos nos módulos das formações continuadas do IEE; e diário de campo. A análise reflexiva dos resultados permitiu verificar que o processo de formação continuada do PRPMEE no RS, especificamente no município de Arroio Grande, foi fundamental para a efetivação de práticas pedagógicas qualificadas nas aulas de Educação Física, pois o professor pesquisado fidelizou os aprendizados construídos durante o processo de formação proposta pelo IEE, apropriando-se da metodologia e colocando-a em prática durante suas aulas.
\end{abstract}

Palavras-chave: Educação física; Formação continuada; Esporte educacional; Ensino.

\begin{abstract}
Education of Physical Education teachers, from 2013 to 2017, was the subject of the partnership established between the Institute of Sport \& Education (IEE) and nine cities in the southern region of the state of Rio Grande do Sul (RS). This study aimed at sharing the experience of the Project Network of Multiplying Partners of Educational Sport (PRPMEE) in the state of RS, involving the implementation, execution and effectuation of Educational Sport practices, besides pointing out the impact of the proposed continuing education on the pedagogical practice of a Physical Education teacher intentionally selected in the city of Arroio Grande. The methodological steps were in accordance with a descriptive, qualitative research, and the information analysis was carried out with the use of Triviños' technique of data triangulation. The instruments used for information collection were the following: semistructured interview; observation of the pedagogical practice; pedagogical materials provided along the IEE modules of continuing education; and field journal. A reflective analysis of the results showed that PRPMEE continuing education process in RS, particularly in the city of Arroio Grande, was fundamental to effect qualified pedagogical practices in Physical Education classes, as the teacher participant followed what was learned in the education process proposed by IEE, by internalizing the methodology and putting it into practice in class.
\end{abstract}

Keywords: Physical education; Continuing education; Educational sport; Teaching. 


\begin{abstract}
Resumen
La formación de profesores/as de Educación Física, entre 2013 y 2017, fue el tema de la alianza establecida entre el Instituto Deporte \& Educación (IDE) y nueve municipios de ciudades de la región sur del Estado de Rio Grande do Sul (RS). Este estudio tuvo como objetivo compartir la experiencia del Proyecto Red de Socios Multiplicadores del Deporte Educativo (PRSMDE), en el Estado de RS, en lo que se refiere a la implementación, realización y efectividad de prácticas en Deportes Educativos, además de señalar el impacto de la formación continua propuesta en la práctica pedagógica de un profesor de Educación Física del municipio de Arroio Grande, escogido para tal propósito. Los pasos metodológicos fueron trazados a través de una investigación descriptiva cualitativa, y el análisis de las informaciones se basó en la técnica de triangulación de datos propuesta por Triviños. Los instrumentos utilizados para recolectar las informaciones fueron: entrevista semiestructurada; observación de la práctica pedagógica; materiales pedagógicos propuestos en los módulos de las formaciones continuas del IDE; y el diario de campo. El análisis reflexivo de los resultados permitió verificar que el proceso de formación continua del PRSMDE en RS, específicamente en el municipio de Arroio Grande, fue fundamental para la efectividad de las prácticas pedagógicas calificadas en las aulas de Educación Física, ya que el profesor investigado fidelizó las lecciones construidas durante el proceso de formación propuesto por el IDE, apropiándose de la metodología y colocándola en práctica durante sus clases.
\end{abstract}

Palabras clave: Educación física; Formación continua; Deporte educativo; Ensenãnza.

\title{
1. Introdução
}

A atual conjuntura político-educacional brasileira, de acordo com a 25 nota do Fórum Nacional de Educação - FNE (2015), explicita o compromisso para o fortalecimento da educação pública, laica, participativa, inclusiva, gratuita e de qualidade socialmente referenciada, no enfrentamento das desigualdades e na garantia dos direitos da educação para todos/as, tendo como lema "Pátria Educadora". Dessa forma, coube aos/ás dirigentes municipais a busca de estratégias para alcançar os níveis desejados de qualidade na educação pública, propiciando formação continuada aos/às educadores/as em todos os níveis e modalidades de ensino, levando em consideração as diversas áreas do conhecimento, pautando os avanços a serem atingidos.

No que se refere à formação de professores/as, as Secretarias de Educação firmaram, no ano de 2013, parcerias com o Ministério da Educação para a realização do Pacto Nacional pela Alfabetização na Idade Certa, o qual contempla professores/as alfabetizadores/as atuantes no primeiro, segundo e terceiro ano do Ensino Fundamental. Especificamente, falando em formação de professores/as de Educação Física, no mesmo ano, as prefeituras de nove cidades da Região Sul do Estado do Rio Grande do Sul (RS) firmaram parceria com o Instituto Esporte \& Educação (IEE) ${ }^{1}$ para a realização do processo formativo intitulado "Rede de Parceiros Multiplicadores de Esporte Educacional", o qual objetiva democratizar a prática do Esporte Educacional por meio da transferência da metodologia do IEE para organizações locais que formam gestores/as e professores/as de diferentes municípios, proporcionando o acesso ao Esporte Educacional de crianças e adolescentes dessas localidades.

Em 2015 o município do Rio Grande, assim como os demais municípios da Região Sul, reuniu a comunidade escolar para discutir as metas e traçar estratégias para o Plano Municipal de Educação (PME) com vigência de 2015 a 2025. Na meta número dois, a qual se refere ao Ensino Fundamental, busca-se universalizar o ensino fundamental de nove anos para toda a população de seis a quatorze anos de idade e garantir que pelo menos 95\% dos/as estudantes concluíssem essa etapa na idade recomendada, até o último ano de vigência deste PME (Câmara Municipal do Rio Grande, 2015, p. 50), apresentando como uma de suas estratégias:

ampliar os momentos de atividades que estimulem as habilidades esportivas nas escolas, visando à disseminação do desporto educacional no Município, com professores habilitados na área, dessa forma afirmando a importância das práticas em Esporte Educacional se fazerem presentes nos currículos escolares.

\footnotetext{
${ }^{1}$ O IEE é uma Organização da Sociedade Civil de Interesse Público (OSCIP) fundada em 2001, pela ex-atleta de voleibol Ana Moser. Tem por objetivo implementar a metodologia do Esporte Educacional em comunidades de baixa renda de todo o território nacional (Instituto Esporte \& Educação [IEE], 2020).
} 
Objetivamos com este estudo compartilhar a experiência da Rede Parceiros Multiplicadores em Esporte Educacional no RS, no que se refere à implementação, realização e efetivação de práticas em Esporte Educacional proporcionadas a partir do processo de formação continuada dos/as professores/as de Educação Física, usando-se da observação e entrevista com um professor participante deste processo para evidenciar aspectos do Esporte Educacional presentes nas aulas regulares de uma escola do município de Arroio Grande.

O presente trabalho está assim subdivido: no primeiro momento será abordado como se constituiu a Rede de Parceiros Multiplicadores de Esporte Educacional no Estado do RS, em seguida como se deu o processo de formação de professores/as, logo serão apresentadas as premissas e objetivos do Esporte Educacional, e por fim a apresentação dos resultados da investigação referente aos impactos da formação continuada na prática pedagógica do professor.

\section{A Constituição da Rede de Parceiros no Rio Grande do Sul}

O Projeto Rede de Parceiros Multiplicadores do Esporte Educacional (PRPMEE) é uma iniciativa do IEE financiado pela Petróleo Brasileiro S.A. - PETROBRAS, sendo este um dos projetos que compõem o Programa Petrobras Esporte e Cidadania. O mesmo foi planejado para transferência de tecnologia baseado no estabelecimento de parcerias com Instituições Sociais - Organizações não Governamentais e Universidades - e Governo - Prefeituras, Secretarias de Educação e Esporte para disseminação de metodologia de ensino do Esporte Educacional. A partir da percepção do IEE de que na maioria dos municípios brasileiros a prática do esporte continua elitizada, super competitiva e desqualificada o projeto objetiva:

democratizar a prática do esporte educacional por meio da transferência da metodologia do IEE para as organizações locais que formam gestores e professores de diferentes municípios, proporcionando o acesso ao esporte educacional de crianças e adolescentes dos municípios, de forma a apoiar a construção de políticas públicas (Rosseto Júnior, 2015, p. 22).

O PRPMEE foi implantado em outros sete Estados brasileiros, além do RS, sendo eles: Alagoas, Amazonas, Bahia, Mato Grosso do Sul, Pernambuco, Rio de Janeiro e São Paulo. O projeto nasceu com dois focos, um diretamente ligado a estruturar e fomentar o Centro de Referência de Esporte Educacional, e o outro vinculado a formação de gestores/as municipais e professores/as de Educação Física (Moser, 2018).

Para este estudo o foco é a formação de professores/as, a qual foi estabelecida após assinatura dos termos de parceria entre o IEE, o parceiro local, representado pela Fundação Sócio Cultural Esportiva do Rio Grande (Funserg), e nove municípios da Região Sul do Estado do RS, sendo eles: Arroio Grande, Canguçu, Chuí, Pelotas, Pedro Osório, Santa Vitória do Palmar, São José do Norte, São Lourenço do Sul e Rio Grande (Moser, 2018). Este último foi o município sede para a realização dos encontros de formação, por ser contemplado pelo Centro de Referência².

Os municípios, após a assinatura do termo de parceria realizado pelos/as prefeitos/as ou seus/suas representantes legais, tiveram a incumbência de divulgar e estreitar laços com 20 professores/as de Educação Física atuantes nas instituições de ensino, para ingresso no processo de formação continuada.

\section{A Formação de Professores/as}

O processo formativo do PRPMEE, no Estado do RS, teve início no ano de 2013 e término no ano de 2017. Ao longo dos quatro anos, foram realizados 23 encontros de formação continuada no Estado. De acordo com Oliveira (2015) a formação contemplou oito encontros no primeiro ano e seis encontros no segundo, cada um com carga horária de 16 horas, totalizando

${ }^{2}$ Centro de Referência em Esporte Educacional era uma sede das redes estaduais, onde ocorriam aulas de esportes para crianças e jovens da região, servindo como referência e disseminador do Esporte Educacional, por meio de aplicação do método do IEE. 
uma certificação de 224 horas ao/à professor/a que participou deste primeiro bloco.

Os conteúdos desenvolvidos nos encontros iniciais abordaram a apresentação da proposta e dos procedimentos metodológicos em Esporte Educacional, além das parcerias necessárias para a constituição dos Núcleos de Esporte Educacional nas escolas. A partir de então, passou a ser realizada a abordagem detalhada da metodologia em Esporte Educacional proporcionada por meio de vivências teóricas e práticas: pedagogia do esporte através do jogo, planejamento de sequências didáticas, realização de eventos esportivos, a importância da construção de instrumentos de avaliação, oficinas de jogos e de construção de materiais (Silva, 2018). Todas elas levando os/as professores/as a pensarem sobre a importância da reflexão-ação-reflexão na constituição de uma prática pedagógica qualificada.

O PRPMEE RS foi renovado no ano de 2015 e com isto foram propostos mais seis encontros no terceiro ano e três no quarto ano de formação, totalizando mais 80 horas de certificação para os/as professores/as que participaram de todos os encontros e tarefas deste segundo bloco. As formações contemplaram as seguintes temáticas: Campeonato em Esporte Educacional; Esportes Alternativos; Inclusão; Educação Física na Educação Infantil e Anos Iniciais; Políticas Públicas; Temas Transversais na Educação Física; Práticas Corporais em Espaços Reduzidos; Educação Física para a Saúde e Educação Física no Sec. XXI (Silva, 2018). Temáticas estas desenvolvidas sob a perspectiva e premissas do Esporte Educacional buscando refletir de que forma abordá-las, garantindo a participação ativa e desenvolvimento integral do/a aluno/a.

Em especial os encontros sobre as temáticas "Temas Transversais na Educação Física e Educação Física no Sec. XXI" foram realizados em forma de Fórum (Prefeitura Municipal do Rio Grande, 2016; Secretaria de Município da Educação [SMED], 2017), eventos estes abertos à comunidade da região, oportunidade na qual os/as professores/as participantes da formação continuada tiveram a possibilidade de compartilhar suas práticas pedagógicas bem-sucedidas por meio de banners, debates e/ou vídeos.

\section{O Esporte Educacional}

O entendimento do termo Esporte Educacional a partir da Lei no 9615 , denominada Lei Pelé (Brasil, 1998) nos remete a uma conceituação vaga em que se deve evitar a seletividade e a hipercompetitividade de seus participantes nas ações realizadas, tanto nos sistemas de ensino quanto em outras formas assistemáticas de educação. Acreditamos que a garantia da inclusão de todos/as os/as participantes na realização das práticas seja o ponto chave dessa conceituação, a qual estará atribuída a uma série de outros aspectos a serem considerados durante a prática, como aponta o Instituto Esporte \& Educação (2017), em que a prática oportunize a tomada de decisão, que respeite o nível de desenvolvimento do/a aluno/a (motor, cognitivo, emocional, psicológico e social) levando este a estabelecer a autocrítica e a autoavaliação, contribuindo, dessa forma, para a emancipação na pratica esportiva, estimulando o pleno exercício da cidadania.

A experiência do IEE é apoiada em mais de uma década de ações de esporte para crianças e adolescentes de comunidades socialmente vulneráveis, através da proposta de ação-reflexão-ação durante processo de formação de professores/as em serviço, verificando a veracidade do método naquele contexto específico. Surgem então, a partir desta vasta experiência e da adaptação de vários estudiosos/as os cinco princípios do Esporte Educacional do IEE. Rosseto Júnior et al. (2012, p. 11) assim os apresentam:

Inclusão de todos: princípio relacionado a criar condições e oportunidades para a participação de todas as crianças e jovens no aprendizado do esporte, desenvolvendo habilidades e competências que possibilitem compreender, transformar, reconstruir e usufruir as diferentes práticas esportivas.

Construção coletiva: princípio relacionado a participação ativa de todos os envolvidos na estruturação do processo de ensino e aprendizagem do esporte, tornando alunos, professores e comunidade corresponsáveis e cogestores do planejamento, execução, avaliação e continuidade dos programas e projetos.

Respeito à diversidade: princípio relacionado a perceber, reconhecer e valorizar as diferenças entre as pessoas no 
que se refere à raça, cor, religião, gênero, biótipo e níveis de habilidades, entendendo a diversidade como uma oportunidade de aprender com as diferenças, diversificando as metodologias de ensino, favorecendo a convivência e a aprendizagem compartilhada.

Educação integral: princípio relacionado à compreensão do esporte como possibilidade de aprendizagem e desenvolvimento cognitivo, psicomotor e sócio-afetivo, desenvolvendo ações pedagógicas que abordem conteúdos nas dimensões: conceitual, atitudinal e procedimental.

Busca da autonomia: princípio relacionado ao entendimento e na transformação do esporte como meio para uma educação emancipatória que se baseia no conhecimento, no esclarecimento e na autorreflexão crítica, promovendo a autonomia, ou seja, a capacidade de os atores sociais analisarem, avaliarem, decidirem, promoverem e organizarem a sua participação e de outros nas diversas práticas esportivas. [ênfase adicionada].

De acordo com Silva et al. (2020, p. 174) os princípios do Esporte Educacional foram apresentados durante a formação do PRPMEE como “norteadores da prática pedagógica dos professores, ou seja, eram como que sinalizadores a guiar o planejamento, estruturar as estratégias e o desenvolvimento das aulas de esporte educacional durante os quatro anos de formação continuada".

O/A professor/a ao planejar suas ações com base nesses princípios, estará valorizando os saberes, cultura e conhecimento dos/as alunos/as, os/as incluindo e fazendo com que os/as mesmos/as se sintam participantes e protagonistas nos processos de ensino e de aprendizagem, construindo de maneira significativa seus novos aprendizados, interagindo com os/as colegas. Dessa forma, proporcionando ao/à professor/a novos caminhos e vivências em cada ação pedagógica, pois cada grupo de alunos/as poderá responder de forma diferenciada, levando o/a aluno/a a diferentes reflexões em uma mesma ação proposta.

O ensino do esporte, nesta perspectiva, segundo Rosseto Júnior et al. (2009, p. 16) tem como objetivo:

Ensinar esporte para todos: não é aceito exclusão, a premissa é de inclusão, proporcionando a participação de todos, pois todos podem aprender a praticar esporte dentro de suas potencialidades e limitações. Ensinar bem esporte para todos: ensino do esporte de maneira que todos aprendam a jogar com competência técnica e tática, pois todos têm o direito de aprender bem para praticar com qualidade. Ensinar mais do que esporte para todos: ir além da prática, fazer com que o aluno reflita sobre temas relacionados a outras áreas tais como: saúde, cultura, cidadania, protagonismo e comunidade.

A partir dos objetivos do Esporte Educacional faz-se necessário levantar orientações didáticas para potencializar os processos de ensino e de aprendizagem, pois as aulas de Educação Física na escola devem partir do que os/as alunos/as já conhecem sobre o conteúdo a ser ensinado, contemplando ações nas dimensões conceitual, procedimental e atitudinal, favorecendo a participação e interação de todos/as os/as agentes envolvidos/as no processo educacional, independente do grau de habilidade motora individual dos/as alunos/as, sempre valorizando a experimentação.

Ao estimular a experimentação motora, essa deverá ser constantemente modificada e adaptada, de modo a possibilitar o sucesso e novas aprendizagens aos/às alunos/as, seja por meio da construção coletiva de novas regras ou, até mesmo, adaptações individuais nos gestos motores e técnicos de alguma modalidade esportiva, que otimize a execução por parte do/a aluno/a.

\section{A Experiência no Município de Arroio Grande}

A seguir apresentamos os achados referentes ao impacto da formação continuada proposta pelo PRPMEE na prática pedagógica de um professor de Educação Física do município de Arroio Grande/RS. Importa destacar que este artigo é oriundo de uma pesquisa de mestrado, a qual englobou um número mais expressivo de informações e dados (Silva, 2018). Este estudo adotou como método a pesquisa qualitativa e o estudo de caso para o seu desenvolvimento. De acordo com Pereira et al. (2018, p.65) o estudo de caso "é uma descrição e análise, a mais detalhada possível, de algum caso que apresente alguma particularidade que o torna especial". 
O professor participante foi escolhido intencionalmente devido a sua efetiva participação na formação continuada do PRPMEE, assim como pela sua disponibilidade e compatibilidade com os horários da pesquisadora. A coleta das informações ocorreu no mês de junho de 2017, com autorização da Secretaria Municipal de Educação do município e do professor participante.

Os instrumentos utilizados para coleta das informações aplicados no estudo foram: entrevista semiestruturada; observação da prática docente em uma turma de oitavo ano do ensino fundamental de uma escola pública rural do município de Arroio Grande, composta por 21 alunos/as; análise dos materiais pedagógicos fornecidos nos módulos das formaç̃es continuadas do IEE, ao longo dos quatro anos de desenvolvimento do PRPMEE; e diário de campo.

Para análise das informações, foi realizada a leitura de todas as fontes de pesquisa, seguido da técnica de triangulação dos dados, que segundo Triviños (1987, p. 138) "tem por objetivo básico abranger o máximo de amplitude na descrição, explicação e compreensão do foco de estudo".

Ao realizar a análise e interpretação dos dados, constatamos que o professor evidencia em sua fala a utilização de dois dos princípios pedagógicos sugeridos pelo IEE para o ensino dos esportes, sendo eles o Princípio Pedagógico da Construção Coletiva (PPCC) e o Principio Pedagógico da Autonomia (PPA), como segue:

"Depois do projeto a gente começou a fazer no município jogos menos competitivos e mais agregadores, jogos entre as escolas sem árbitros, sem juízes para eles mesmos verem o que erraram indicarem, pedirem a falta, quando foi ou não. Então, teve uma mudança, aspectos positivos.

Além disso, a gente tenta fazer torneios que integram os alunos, que eles tentam fazer suas regras, aqui na escola a gente fez torneio de handebol que eles mesmos fizeram suas regras.

Agora estamos trabalhando num esporte que os alunos desenvolveram juntamente com o professor, o Habilibol, os alunos decidiram que seria esse nome porque ele trabalha muitas habilidades. Ele tem princípios do handebol, como só pode dar três passos com a posse de bola na mão, cinco segundos com a bola na mão, o principio de fazer o ponto vêm do futebol americano em que se tem que atravessar uma linha, no nosso caso os cones. Esporte que não tem contato, a gente adaptou, tem um pouco do Rugby, a bola a gente está como uma inicial de futebol americano."

Ao analisar os resultados do instrumento de observação da aula de Educação Física do professor, podemos constatar a presença de, pelo menos, três Princípios Pedagógicos do Esporte Educacional propostos pelo IEE, sendo eles: o Princípio Pedagógico do Respeito à Diversidade (PPRD), o PPCC e o Princípio Pedagógico da Inclusão de Todos (PPIT).

Tais evidências foram confirmadas quando o professor propôs a divisão das equipes de forma mista, garantindo o cumprimento de regras que minimizam o contato físico, visando proteger os/as alunos/as de confrontos que pudessem a vir machucar alguém, além do cuidado constante para garantir a vivência prática aos/às alunos/as, preocupando-se para que todos/as jogassem ativamente, durante o mesmo tempo, por toda a aula.

Zabala (1998, p. 91) denomina as ações de atividades conjuntas entre professores/as e alunos/as como "um processo de construção compartilhada". Desse modo, com base nas informações coletadas, podemos apurar que, naquele contexto educativo, o aprendizado está pautado em escolhas e em ações que permitem aos/às alunos/as interagir e construir o seu aprendizado. Durante a observação da prática acompanhamos o jogo criado pela turma - o Habilibol (Habili de habilidade e bol de bola), assim denominado por possuir em sua constituição características que lembram as diferentes modalidades esportivas, mas acima de tudo, demandar habilidades de manejo com a bola.

Para compreender a relação da aula observada com possíveis contribuições das formações continuadas, foram analisados os acervos referentes aos materiais pedagógicos da formação proposta pelo IEE. Assim, constatamos que as propostas de como desenvolver o ensino e o aprendizado do esporte, se utilizando dos Princípios Pedagógicos do Esporte Educacional, estiveram presentes e foram discutidas em todos os módulos do programa método.

Em especial o PPCC, o qual foi identificado tanto na entrevista quanto na observação, foi discutido nos seguintes 
módulos: I (apresentação dos Princípios); IV (Planejamento pedagógico - Sequências didáticas 1); V (Evento de Esporte Educacional - estrutura e funcionamento; Planejamento pedagógico - Sequências didáticas 2); X (Oficina de Construção de Materiais Pedagógicos - Danças, lutas e ginásticas); XII (Introdução à pedagogia das atividades circense) e XIII (Campeonato de Esporte Educacional - estrutura e funcionamento) onde foi dado ênfase de como trabalhar na perspectiva de envolver o/a aluno/a durante todo o processo de planejamento, execução e avaliação da ação, seja durante as aulas ou durante eventos esportivos.

Perante a triangulação realizada (Figura 1) e das evidências encontradas, constatamos que a prática pedagógica do professor participante se aproxima do método de ensino do Esporte Educacional proposto pelo IEE, visto que o mesmo se utiliza dos Princípios Pedagógicos do Esporte Educacional tanto nas aulas quanto no planejamento e execução de atividades realizadas no município, denominadas por ele de "mais agregadoras".

Figura1. Triangulação das informações coletadas.

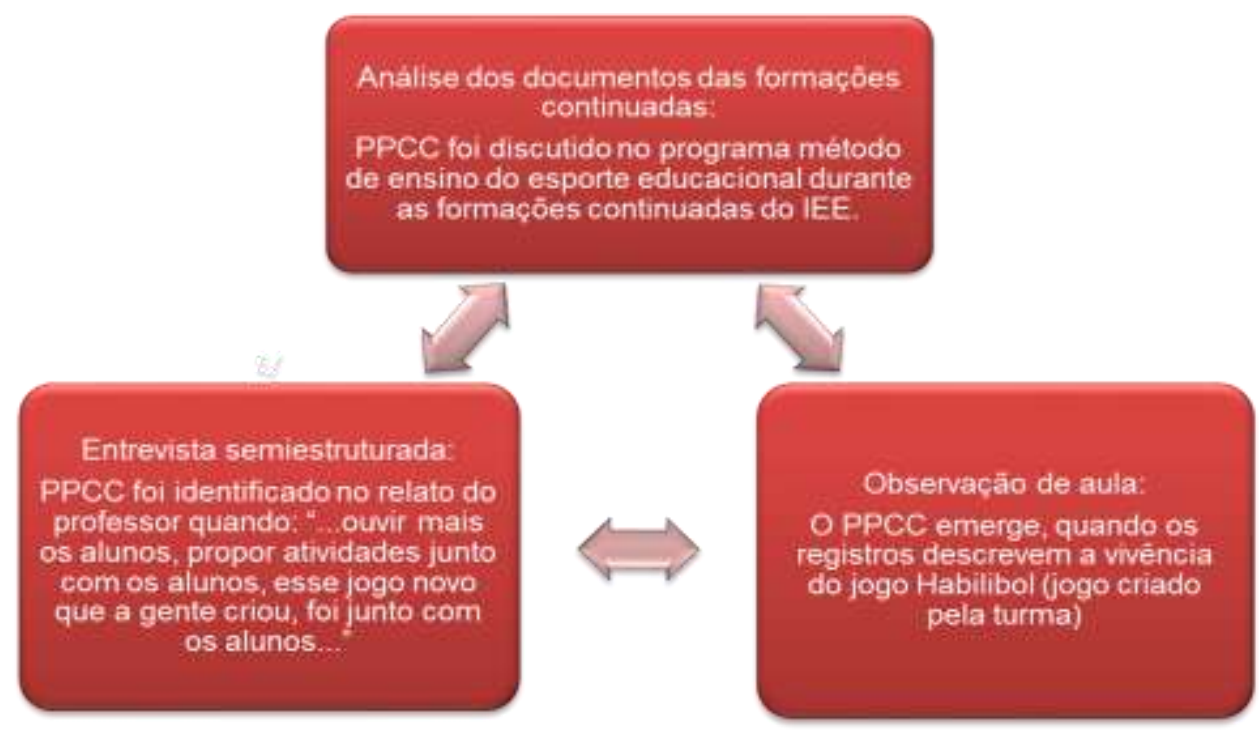

Fonte: Autores (2019).

Durante a entrevista com o professor, quando questionado sobre as mudanças que ocorreram em sua prática pedagógica a partir das formações continuadas, o mesmo destaca as seguintes percepções:

"No fato de ouvir mais os alunos, propor atividades junto com os alunos, esse jogo novo que a gente criou, foi junto com os alunos, então, acho que as formações contribuíram nesse sentido, não que a gente não fizesse antes, mas o projeto incentiva mais essa parte de atitudes, conceitos de identificar tudo isso, acredito que neste ponto contribuiu bastante".

Acreditamos que a estratégia escolhida pelo professor, de oportunizar espaço de criação de jogos aos/às alunos/as, tenha sido motivada pelas experiências durante as formações continuadas do IEE e por isso a aplicação do PPCC ter sido evidenciado em sua prática pedagógica. Ademais, podemos perceber que, de modo geral, a prática pedagógica do professor participante do estudo foi subsidiada também por outros Princípios Pedagógicos, o que reforça a importância da formação continuada proposta pelo PRPMEE no que se refere ao ensino do Esporte Educacional e a sua influência na Educação Física escolar.

Também foi possível perceber, de forma geral, que os objetivos do Esporte Educacional foram contemplados, uma 
vez que as ações proporcionaram ensinar esporte para todos/as, onde não houve exclusão, todos/as participaram ativamente, aprendendo a praticar esporte dentro de suas potencialidades e limitações. Além disso, percebemos que o professor ensinou mais do que esporte para todos/as, pois os/as alunos/as tiveram a oportunidade de criar um jogo e ir além da prática, fazendo com que os/as mesmos/as refletissem sobre saúde, cultura esportiva e protagonismo.

\section{Considerações Finais}

A proposta da formação do PRPMEE contemplou uma necessidade nacional, sendo, para os/as profissionais da Educação Física, uma possibilidade de formação continuada pautada nos avanços a serem atingidos, os quais se fizeram presentes na redação dos Planos Municipais de Educação das cidades da região Sul do RS, basicamente voltados à promoção de atividades de desenvolvimento e estímulo a habilidades esportivas nas escolas, que busquem disseminar o Esporte Educacional, utilizando como base as discussões realizadas durante os encontros formativos.

A análise reflexiva dos resultados nos permite verificar que o processo de formação continuada do PRPMEE no RS, especificamente no município de Arroio Grande, foi fundamental para a efetivação de práticas pedagógicas qualificadas nas aulas de Educação Física, pois o professor pesquisado fidelizou os aprendizados construídos durante o processo de formação proposta pelo IEE, apropriando-se da metodologia e colocando em prática durante suas aulas.

Tais aprendizados evidenciados a partir de ações pensadas, planejadas e avaliadas em conjunto com os/as alunos/as, que se demonstraram ativos/as no processo educacional, evidenciam a utilização do PPCC "onde os professores juntamente com os alunos são autores de seus conhecimentos, não meros reprodutores" (Rosseto Júnior, 2015, p. 63). Além disso, os resultados reforçam a importância da proposição de formações continuadas aos/às professores/as, as quais aliem a teoria e a prática.

Por fim, destacamos que novas investigações com foco em formações continuadas podem ser realizadas, com possibilidade de expandir para outras localidades e outros/as participantes do projeto PRPMEE, ampliando os espaços de escuta e observações. Também sinalizamos como sugestão de pesquisas futuras averiguarem as influências da formação continuada de longa duração para a qualidade das práticas pedagógicas desenvolvidas, bem como as possibilidades de troca de experiências entre os/as docentes durante as formações.

\section{Referências}

Brasil. (1998). Lei no 9.615, de 24 de março de 1998. Institui normas gerais sobre desporto e dá outras providências. Presidência da República. http://www.planalto.gov.br/ccivil_03/LEIS/L9615Compilada.htm.

Câmara Municipal do Rio Grande. (2015). Plano Municipal de Educação. https://www.riogrande.rs.gov.br/smed/wp-content/uploads/2015/08/20150808lei_7.911_anexo_-_plano_municipal_de_educacao.pdf.

Fórum Nacional de Educação. (2015). 25 a nota do Fórum Nacional de Educação. conjuntura político-educacional. http://fne.mec.gov.br/images/notas/25NotaPublica09042.pdf.

Instituto Esporte e Educação. (2017). Estratégias de Ensino do Esporte Educacional. Gráfica Paulo’s.

Instituto Esporte \& Educação. (2020). O Instituto Esporte \& Educação. https://esporteeducacao.org.br/o-instituto-esporte-educacao.

Moser, A. (2018). Resultados e impactos do projeto Rede de Parceiros Multiplicadores de esporte educacional. Gráfica Paulo’s.

Oliveira, A. P. M. (2015) A formação continuada de professores na rede multiplicadora de esporte educacional. In: Rosseto Júnior, A. J., Oliveira, A. P. M., Machado, C. E. B., Patrício, C. E., Kafer, E. de S., Tavares, E., Santos, F. D. dos., Alves, F. A., Costa, L. B., Costa, L. A. da., Capela, P., Oliveira, L. G., Quadro, P. D. de., Mendes, R. I., Gonçalves, V., \& Soares, V. Esporte educacional: A Experiência do Centro de Referência Esportiva Rio Grande (p. 107112). Insular.

Pereira, A. S., Shitsuka, D. M., Parreira, F. J., \& Shitsuka, R. (2018). Metodologia da pesquisa científica UFSM. https://repositorio.ufsm.br/bitstream/handle/1/15824/Lic_Computacao_Metodologia-Pesquisa-Cientifica.pdf?sequence=1. 
Research, Society and Development, v. 10, n. 2, e28210212560, 2021

(CC BY 4.0) | ISSN 2525-3409 | DOI: http://dx.doi.org/10.33448/rsd-v10i2.12560

Prefeitura Municipal do Rio Grande (2018, 18 de novembro). Prefeitura apoia realização do Fórum da Rede de Parceiros Multiplicadores de Esporte Educacion https://www.riogrande.rs.gov.br/consulta/index.php/noticias/detalhes+2ee9a,,prefeitura-apoia-realizacao-do-forum-da-rede-de-parceirosmultiplicadores-de-esporte-educacional.html\#.YAsigHZKiHs.

Rosseto Júnior, A. J., Ardigó Junior, A., Costa, C. M., \& D’Angelo, F. (2009). Jogos educativos: estrutura e organização da prática. (5a ed.), Phorte.

Rosseto Júnior, A. J., Costa, C. M., \& D’Angelo, F. L. (2012). Práticas pedagógicas reflexivas: unidade didática como instrumento de ensino e aprendizagem (2. ed. Revisada). Phorte.

Rosseto Júnior, A. J., Oliveira, A. P. M., Machado, C. E. B., Patrício, C. E., Kafer, E. de S., Tavares, E., Santos, F. D. dos, Alves, F. A., Costa, L. B., Costa, L. A. da., Capela, P., Oliveira, L. G., Quadro, P. D. de., Mendes, R. I., Gonçalves, V., \& Soares, V. (2015) Esporte educacional: a experiência do centro de referência esportiva de Rio Grande. Insular.

Secretaria do Município da Educação - Rio Grande - RS. (2017, 17 de julho). $2^{\circ}$ Fórum da Rede de Parceiros Multiplicadores do Esporte Educacional" acontecerá nesta terça-feira, 04. https://www.riogrande.rs.gov.br/smed/?p=22096.

Silva, P. R. L. da. (2018). O impacto da formação continuada na prática pedagógica de professores de Educação Física [Dissertação de Mestrado, Universidade Federal de Pelotas].

Silva, P.R.L. da, Montiel, F.C, Rosseto Júnior, A.J., \& Pinheiro, E. S. (2020). Formação continuada de professores e a aplicação dos princípios pedagógicos do esporte educacional. Revista Humanidades e Inovação, 7(10), 169-185. https://revista.unitins.br/index.php/humanidadeseinovacao/article/view/2352.

Trivinos, A. N. S. (1987). Introdução à pesquisa em Ciências Sociais - A pesquisa qualitativa em educação. Atlas.

Zabala, A. (1998). A prática educativa: como ensinar. Artmed. 